\title{
Characteristics of Trypsin-like Activity in Subgingival Plaque Samples
}

\author{
W.A. BRETZ and W.J. LOESCHE
}

School of Dentistry, The University of Michigan, Ann Arbor, Michigan 48109

Previous studies have demonstrated that the hydrolysis of the trypsin substrate N-benzoyl-DL-arginine-2-naphthylamide (BANA), by subgingival plaque obtained from a single site, correlates best with the numbers and proportions of spirochetes in plaque samples and may serve as an indicator of clinical disease. In this investigation, we determined whether the association between BANA hydrolysis and spirochetes could be obtained in pooled subgingival plaque samples. Concomitantly, the characteristics of this reaction in terms of substrate type and concentration, microbial numbers needed to give a positive reaction as assessed by microscopic counts, rapidity of hydrolysis, and the effect of $\mathrm{pH}$ and various additives on the plaque $B A N A$ hydrolytic activity have been studied in pooled plaque samples from patients who were periodontally healthy or diseased. In addition, it was determined whether BANA hydrolytic activity found in subgingival plaque reflected contributions from saliva and supragingival plaque. Results indicated that the assay can best be performed with $0.67 \mathrm{mmol} / \mathrm{L}$ BANA at $\mathrm{pH}$ 7.0. EDTA and $\mathrm{CaCl}_{2}$ gave a slight inhibition and DTT a slight enhancement of the BANA reaction by the pooled plaque suspensions. The majority of the reactions $(85 \%)$ developed their full color after overnight incubation. BANA hydrolysis was not found in saliva and occurred with much greater frequency in subgingival plaque as opposed to supragingival plaque. Analysis of the data indicated that BANA hydrolysis by pooled subgingival plaque samples is a suitable test for the detection of spirochetes when two or three spirochetes per high microscopic field are present in the sample.

J Dent Res 66(11):1668-1672, November, 1987

\section{Introduction.}

In recent years, evidence has been presented which suggests a specific bacterial etiology in many forms of periodontal diseases. The association of a limited number of bacterial species-i.e., Haemophilus (Actinobacillus) actinomycetemcomitans (Zambon, 1985), Bacteroides gingivalis (Slots et al., 1985; Loesche et al., 1985), Bacteroides forsythus, Wolinella recta (Dzink et al., 1985), and spirochetes (Loesche et al., 1985) - with various forms of periodontal disease allows for the development of diagnostic tools that are based upon the detection of one or more of these organisms and/or their overgrowth in plaque. The detection and/or enumeration of these species by cultural or microscopic methods is time-consuming and labor-intensive. An ideal approach would be the development of a diagnostic test for the presence and/or levels of these organisms that is simple, inexpensive, and reliable.

B. gingivalis, a Capnocytophaga species phenotypically similar to $C$. gingivalis, Treponema denticola, a small spirochete (Laughon et al., 1982a), and B. forsythus (Tanner et al., 1985 ) possess a trypsin-like enzyme which can be detected by a biochemical chromogenic reaction. Previous studies (Loesche et al., 1987) have demonstrated that the hydrolysis of the trypsin substrate N-benzoyl-DL-arginine-2-naphthylamide (BANA) by subgingival plaque obtained from a single site correlates best with the numbers and proportions of spirochetes in plaque samples and may serve as an indicator of clinical disease. In

Received for publication July 23, 1986

Accepted for publication July 29, 1987

This research was supported by Public Health grants DE 02731 and DE 06030 from the National Institute of Dental Research. this investigation, we determined whether the same association between BANA hydrolysis and spirochetes could be obtained in pooled subgingival plaque samples, since it is likely in practice that a clinician would pool such samples so as to obtain information from one test per patient. In addition, the characteristics of this reaction in terms of substrate type and concentration, microbial numbers needed to give a positive reaction, rapidity of hydrolysis, $\mathrm{pH}$ optimum, and the effects of additives (enhancers and/or inhibitors) on the plaque BANA hydrolytic activity have been studied in patients who were periodontally healthy or diseased.

\section{Materials and methods.}

Subgingival plaque samples were collected and pooled from three or four sites per patient by means of a curette after the supragingival plaque had been removed and discarded. In a separate experiment, using a second group of individuals, supragingival plaque samples were removed from teeth that were periodontally healthy or diseased. These pooled samples were transferred to a vial containing $0.6 \mathrm{~mL}$ of Sorensen phosphate buffer ( $\mathrm{pH} 7.2,0.15 \mathrm{~mol} / \mathrm{L}$ monopotassium phosphate, 0.15 $\mathrm{mol} / \mathrm{L}$ disodium phosphate) and dispersed for 20 seconds by means of a vortex mixer; $0.05 \mathrm{~mL}$ of this plaque suspension was removed for microscopic count, with the remainder used for the various experiments.

For the microscopic counts, $0.01 \mathrm{~mL}$ of the aliquot used for the microscopic analysis was placed on a glass slide, covered with a cover slip, sealed, and examined by dark-field microscopy. The remaining plaque suspension was further divided into several $0.05-\mathrm{mL}$ aliquots and added to $0.1 \mathrm{~mL}$ BANA to give a final concentration of $0.67 \mathrm{BANA} \mathrm{mmol} / \mathrm{L}$. The BANA stock solution was prepared by the addition of $44 \mathrm{mg}$ to $1 \mathrm{~mL}$ of dimethyl sulfoxide and was diluted 1:100 in Sorensen phosphate buffer. The samples were incubated overnight at $37^{\circ} \mathrm{C}$, and the color was developed by the addition of a drop of $0.1 \%$ fast garnet (Laughon et al., 1982a). The results were read by eye with the aid of a color chart and with scoring methods as described elsewhere (Loesche et al., 1987).

Optimal concentration of BANA. - The purpose of this experiment was to determine optimal concentration for plaque assay. Previous studies (Laughon et al., 1982b) using pure strains of Bacteroides gingivalis showed $1 \mathrm{mmol} / \mathrm{L}$ BANA in the final reaction mixture to be the optimal concentration. We wanted to determine whether or not this concentration was also optimal for plaque assays. The concentrations tested ranged from $0.67 \mathrm{mmol} / \mathrm{L}$ to $13.4 \mathrm{mmol} / \mathrm{L} \mathrm{BANA}$ in the final reaction mixture.

Rapidity of hydrolysis. - Plaque samples were incubated at $37^{\circ} \mathrm{C}$, and the color reactions were read after 30 minutes, one hour, and 18 hours (overnight incubation). The first two time intervals were chosen to duplicate a time interval that might occur during a patient's visit to the dentist.

Microbial numbers needed to give a positive reaction. - The number of bacteria per high-power microscopic field (hpf) and the number of spirochetes per hpf required to give a positive reaction were determined by dark-field microscopy. Each plaque suspension was examined until either 200 organisms or the 
number of organisms in $20 \mathrm{hpf}$ was enumerated. The single cells were identified as spirochetes, selenomonads, vibrio-like, motile rods, fusiforms, non-motile rods, or cocci. The numbers of spirochetes and bacteria per hpf were correlated with the BANA reaction.

In separate experiments, the BANA reagent $(0.67 \mathrm{mmol} / \mathrm{L})$ was added to undiluted plaque suspension $(0.1 \mathrm{~mL})$ and to $1: 2$ and 1:10 dilutions thereof. After overnight incubation and addition of the fast garnet color developer, the amount of color was determined and correlated with the number of bacteria and/ or spirochetes per hpf. In this manner, it was possible to estimate the minimal number of bacteria or spirochetes needed to give a positive BANA reaction.

Substrate type. - Recently, Ohta et al. (1986) isolated and characterized a trypsin-like enzyme from Treponema denticola which was capable of hydrolyzing N-benzoyl-L-arginine-p-nitroanilide (BAPNA) as well as BANA. This substrate, unlike BANA, does not require an additional reagent to develop its color. BANA and BAPNA substrates were compared at different concentrations using the same plaque suspensions.

Effect of $p H$ on BANA hydrolysis. - The plaque samples were normally suspended in Sorensen phosphate buffer $(\mathrm{pH} 7.2)$ and added to the BANA solution, which was also at $\mathrm{pH} 7.2$. In this study, the plaque suspensions were added to BANA stock solutions that had been prepared in Sorensen phosphate buffer at $\mathrm{pHs} 6.0,7.0$, and 8.0 , so as to mimic those $\mathrm{pHs}$ which could be found in resting subgingival plaque. These plaqueBANA mixtures were adjusted to yield the respective $\mathrm{pHs}$ by addition of $0.1 \mathrm{~mol} / \mathrm{L} \mathrm{HCl}$ or $\mathrm{KOH}$.

Additives. - The previous study used plaque suspended in reduced transport fluid (RTF) for the measurement of BANA hydrolysis (Loesche et al., 1987). Since RTF contains $\mathrm{CaCl}_{2}$, EDTA, and dithiothreitol (DTT) as additives, the effects of these compounds on the plaque BANA hydrolytic activity were determined by addition of $0.01,0.1$, or $1 \mathrm{mmol} / \mathrm{L}$ of these reagents to the BANA-plaque-Sorensen buffer mixture previously described.

Statistical analysis. - The data were entered, via a customized program, into files suitable for computer processing. The bacterial counts, as well as the total spirochetal counts and their relation to test results, were submitted to analysis of variance (ANOVA) and the nonparametric Kruskal-Wallis and chi-square tests. These statistical analyses were performed by means of MIDAS, the statistical program of the Michigan Terminal System.

\section{Results.}

The majority of the samples hydrolyzed BANA over a 20fold concentration range $(0.67$ to $13.4 \mathrm{mmol} / \mathrm{L})$ (Table 1$)$. The highest proportions of positive reactions and the lowest proportions of weak positive reactions were seen at $0.67 \mathrm{mmol} / \mathrm{L}$ BANA, and this concentration was chosen for the remaining

TABLE 1

EFFECT OF BANA CONCENTRATION ON ABILITY OF PLAQUE TO HYDROLYZE BANA

\begin{tabular}{|c|c|c|c|c|}
\hline $\begin{array}{c}\text { BANA } \\
\text { hydrolysis } \\
(\mathrm{n}=17)\end{array}$ & $(0.67 \mathrm{mmol} / \mathrm{L})^{\mathrm{a}}$ & $(3.3 \mathrm{mmol} / \mathrm{L})$ & $(6.7 \mathrm{mmol} / \mathrm{L})$ & $(13.4 \mathrm{mmol} / \mathrm{L})$ \\
\hline$\%$ Positive & $76^{*}$ & $64^{*}$ & $64^{*}$ & $47^{*}$ \\
\hline$\%$ Wk Pos. & 6 & 24 & 12 & 18 \\
\hline$\%$ Negative & 18 & 12 & 24 & 35 \\
\hline
\end{tabular}

studies. Fifteen percent of the positive reactions at these concentrations developed their maximal color in one hour, while $85 \%$ of the reactions required overnight incubation for maximal color development. The samples which exhibited a rapid color change had high levels of spirochetes per hpf, i.e., above 20 spirochetes per hpf.

There was a strong positive relationship between BANA hydrolysis and both the number of spirochetes per hpf and the number of bacteria per hpf in the subgingival plaques (Table 2). An average of 6 spirochetes per hpf and 15 bacteria per hpf was associated with weakly positive reactions, suggesting that these values were near the detection limit for BANA hydrolysis. A distribution analysis of the numbers of spirochetes and bacteria per hpf in the BANA-positive and BANA-negative plaque samples indicated that the detection limit was lower, being about 2 spirochetes and 6 bacteria per hpf, respectively. Thus, $90 \%$ of the BANA-positive plaque samples had 2.4 spirochetes or more per hpf, whereas only $25 \%$ of the BANAnegative samples had more than 1.8 spirochetes per hpf (Table $3)$. Ninety percent of the BANA-positive samples had 6.4 bacteria or more per hpf, whereas only $25 \%$ of the BANA-negative samples had more than 6.5 bacteria per hpf.

A similar detection limit was estimated via a different approach. Plaque suspensions and various dilutions thereof were incubated with the BANA reagent. BANA-positive reactions occurred in samples that averaged 27 bacteria and 15 spirochetes per hpf (Table 4). A 1-to-2 dilution of these samples did not change the proportions of BANA-positive or weakly positive plaque, but a 1-to- 10 dilution converted $90 \%$ of these samples to BANA-negative. The remaining BANA-positive or weakly positive samples had at least 7 bacteria and 2 spirochetes per hpf, whereas in the now-BANA-negative samples, the bacteria averaged $2.1 \mathrm{per}$ hpf and the spirochetes $1.3 \mathrm{per}$ hpf (Table 4).

\section{TABLE 2}

TEST RESULTS AND THEIR RELATIONSHIP TO THE NUMBER OF BACTERIA AND SPIROCHETES PER HIGH-POWER MICROSCOPIC FIELD (hpf) IN SUBGINGIVAL PLAQUES

\begin{tabular}{lrcc}
\hline $\begin{array}{c}\text { BANA } \\
\text { Hydrolysis }\end{array}$ & $\mathrm{n}$ & $\begin{array}{c}\text { Bact/hpf } \\
\text { (mean } \pm \text { SD) }\end{array}$ & $\begin{array}{c}\text { Spir/hpf } \\
\text { (mean } \pm \text { SD) }\end{array}$ \\
\hline Positive & 113 & $24.9 \pm 24.1$ & $13.5 \pm 15.1$ \\
Wk Pos. & 65 & $15.3 \pm 10.3$ & $6.2 \pm 5.4$ \\
Negative & 123 & $5.7 \pm 5.3$ & $1.4 \pm 1.6$ \\
ANOVA & & $\mathrm{p}<0.0001$ & $\mathrm{p}<0.0001$ \\
Kruskal-Wallis & & $\mathrm{p}<0.0001$ & $\mathrm{p}<0.0001$ \\
\hline
\end{tabular}

TABLE 3

FREQUENCY DISTRIBUTION OF SPIROCHETES PER HIGHPOWER FIELD (hpf) AND BACTERIA PER hpf IN BANA-POSITIVE AND BANA-NEGATIVE PLAQUE SAMPLES

\begin{tabular}{cccc}
\hline \hline & \multicolumn{2}{c}{ BANA } & $\begin{array}{c}\text { Ratio } \\
\text { Percentile }\end{array}$ \\
\hline \multicolumn{5}{c}{ Positive } & Negative & \\
0.10 & \multicolumn{2}{c}{ Spirochetes/hpf } & \\
0.25 & 2.4 & 0.25 & 9.2 \\
0.50 & 4.5 & 0.35 & 12.8 \\
0.75 & 7.2 & 0.7 & 10.4 \\
0.90 & 15.2 & 1.8 & 8.4 \\
& 38.7 & 3.75 & 10.3 \\
0.10 & & & \\
0.25 & 6.4 & & \\
0.50 & 10.0 & 1.4 & 4.6 \\
0.75 & 15.4 & 2.7 & 3.7 \\
0.90 & 25.6 & 4.0 & 3.9 \\
& 41.6 & 6.5 & 3.9 \\
\end{tabular}


TABLE 4

EFFECT OF DILUTION ON THE ABILITY OF POOLED SUBGINGIVAL PLAQUE SAMPLES TO HYDROLYZE BANA

\begin{tabular}{lccr}
\hline \hline $\begin{array}{l}\text { BANA } \\
\text { hydrolysis } \\
(\mathrm{n}=68)\end{array}$ & $\begin{array}{c}\text { Undiluted } \\
\text { Plaque }\end{array}$ & \multicolumn{2}{c}{ Diluted Plaque } \\
\hline \% positive & 67.5 & 67.5 & $1 / 10$ \\
$\quad$ bacteria/hpf & 27.0 & 13.5 & 2.5 \\
$\quad$ spirochetes/hpf & 15.0 & 7.5 & 3.0 \\
\% weak positive & 32.5 & 30.0 & 7.0 \\
$\quad$ bacteria/hpf & 19.0 & 9.5 & 7.0 \\
spirochetes $/$ hpf & 7.0 & 4.0 & 2.0 \\
\% negative & & 2.5 & 90.0 \\
bacteria/hpf & & 2.0 & 2.1 \\
spirochetes $/$ hpf & & 1.0 & 1.3 \\
\hline
\end{tabular}

These experiments showed that increased numbers of spirochetes and bacteria per hpf were significantly related to BANA hydrolysis. The spirochetes were a major component of the bacteria per hpf, comprising about $40 \%$ of the flora, i.e., average $44.1 \%$, median $42.8 \%$. Thus, it is possible that the relationship between bacteria per hpf and BANA hydrolysis could reflect in large part the contributions of the spirochetes to the total bacterial count. We reasoned that if the nonspirochetal bacteria were making a contribution to the BANA hydrolysis that was equal to that of the spirochetes, there would be no difference in the number of spitochetes and bacteria per hpf when a ratio of BANA-positive to BANA-negative plaque samples was calculated.

In the data presented in Table 3 , the number of spirochetes per hpf, when the ratio of positive to negative BANA samples was determined, ranged from 8 to 13 , with a median value of 10. The corresponding ratio for the number of bacteria per hpf ranged from 3.5 to 4.6 , with a median value of 3.9 . This suggested that the spirochetes were making the greater contribution to the positive BANA reactions, since the ratio between a positive and a negative reaction was 10 , as opposed to 4 when all the bacteria were considered. If the nonspirochetal organisms were making an equal contribution, then their ratio would also have been about 10 . In reality, given the fact that the spirochetes comprised about half the bacteria in the plaque, then the decrease in the ratio from 10 to 4 almost reflects the dilution of the spirochete count by BANA-negative bacteria. These calculations suggest that the spirochetes, rather than the nonspitochetal organisms, were making the major contribution to the BANA-positiveness of the plaque.

The relative contribution of the spirochetes to the positive BANA activity of the plaque samples was also assessed by measurement, in separate experiments, of the BANA activity of supragingival plaque samples that would not be expected to have the same dominant spirochetal composition as subgingival plaque. The supragingival plaque samples were removed, but instead of being discarded, were incubated with the BANA reagent. The subgingival samples collected at the same time from the same teeth were incubated independently with the BANA reagent. Sixty-two percent of the subgingival samples were BANA-positive, whereas only $15 \%$ of the supragingival samples were BANA-positive (Table 5). This indicates that the microbes responsible for BANA hydrolysis resided primarily in the subgingival plaque.

Additional studies were performed to see whether the spirochetes could contribute to the BANA hydrolysis observed in the supragingival plaque. These supragingival plaque samples were mainly BANA-negative, despite the presence of high numbers of bacteria per hpf (Table 6). However, there was a significant positive relationship between BANA hydrolysis and
TABLE 5

EFFECT OF SUPRAGINGIVAL AND SUBGINGIVAL PLAQUE ON BANA HYDROLYSIS

\begin{tabular}{lcc}
\hline & Supragingival $^{\alpha}$ & Subgingival $^{\mathrm{a}}$ \\
& 26 & 26 \\
No. of Samples & $\%$ & $\%$ \\
\hline Positive & 15 & 62 \\
Wk Pos. & 12 & 3 \\
Negative & 73 & 35 \\
\hline
\end{tabular}

aSupragingival and subgingival test results significantly different by chisquare analysis, $\mathrm{p}<0.005$.

TABLE 6

RELATIONSHIP BETWEEN BANA HYDROLYSIS AND THE NUMBER OF BACTERIA/hpf AND SPIROCHETES/hpf IN SUPRAGINGIVAL PLAQUES

\begin{tabular}{|c|c|c|c|c|}
\hline $\begin{array}{l}\text { BANA } \\
\text { Hydrolysis }\end{array}$ & $\begin{array}{c}\text { No. of } \\
\text { Samples }\end{array}$ & Bact/hpf & Spir/hpf & $\begin{array}{c}\% \\
\text { Spirochetes }\end{array}$ \\
\hline Positive & 1 & 9.4 & 1.3 & 13.8 \\
\hline Wk Pos. & 4 & $10.3 \pm 2.5^{a}$ & $1.0 \pm 0.2$ & $10.2 \pm 1.2$ \\
\hline Negative & 35 & $15.9 \pm 11.4$ & $0.4 \pm 0.3$ & $1.5 \pm 1.8$ \\
\hline ANOVA & & NS & $p<0.001$ & $p<0.0001$ \\
\hline
\end{tabular}

${ }^{a}$ Average plus or minus standard deviation.

$\mathrm{NS}=$ Not significantly different.

TABLE 7

EFFECT OF PH ON BANA OR BAPNA HYDROLYSIS BY POOLED PLAQUE*

\begin{tabular}{lccc}
\hline \hline BANA & & pH & \\
hydrolysis & 6.0 & 7.0 & 8.0 \\
$(\mathrm{n}=27)$ & $(\%)$ & $(\%)$ & $(\%)$ \\
\hline Positive & 44 & 52 & 52 \\
Wk Pos. & 19 & 19 & 19 \\
Negative & 37 & 29 & 29 \\
\hline BAPNA & & & \\
hydrolysis & & & $(\%)$ \\
(n=15) & $(\%)$ & $(\%)$ & 47 \\
Positive & 47 & 47 & 20 \\
Wk. Pos. & 20 & 20 & 33 \\
Negative & 33 & 33 & \\
\hline
\end{tabular}

* Differences in results are not statistically significant.

the absolute number of spirochetes, i.e., spirochete per hpf, and relative number of spirochetes, i.e., \% spirochetes. In those few samples that were positive or weakly positive, the spirochetes averaged about 1 organism per hpf but comprised about $10 \%$ of the flora.

There were no differences in hydrolysis of BANA and BAPNA substrates at the tested concentrations. Both BANA and BAPNA were equally hydrolyzed by plaque suspensions over the $\mathrm{pH}$ range of 6.0 to 8.0 (Table 7). The addition of EDTA and $\mathrm{CaCl}_{2}$ over a 100 -fold concentration range gave a slight inhibition and DTT a slight enhancement of BANA hydrolysis by subgingival plaque samples (Table 8).

There is the possibility that proteases produced by PMNs present in crevicular fluid and/or by bacteria present in saliva or supragingival plaque could be contributing to the BANA hydrolysis observed in these subgingival plaque samples. Loesche et al. (1987) have shown that peripheral blood and crevicular fluid PMNs did not hydrolyze BANA. We were unable to detect BANA hydrolysis in $0.1 \mathrm{~mL}$ of saliva collected from 15 patients who were either healthy or periodontally diseased (data not shown). This volume of saliva is about 20 times the amount of saliva that could have contaminated 
TABLE 8

EFFECT OF VARIOUS ADDITIVES ON BANA HYDROLYSIS BY POOLED PLAQUE SAMPLES

\begin{tabular}{|c|c|c|c|c|}
\hline \multirow{2}{*}{$\begin{array}{l}\text { BANA } \\
\text { hydrolysis }\end{array}$} & \multicolumn{4}{|c|}{$\mathrm{pH} 7.0$} \\
\hline & Control & $0.01 \mathrm{mmol} / \mathrm{L}^{\mathrm{a}}$ & $0.1 \mathrm{mmo} / \mathrm{L}$ & $1 \mathrm{mmol} / \mathrm{L}$ \\
\hline \multicolumn{5}{|c|}{$\mathrm{CaCl}_{2}$ addition $(\mathrm{n}=14)$} \\
\hline \% Positive & 14 & 14 & 14 & 14 \\
\hline$\%$ Wk Pos. & 29 & 7 & 7 & 7 \\
\hline$\%$ Negative & 57 & 79 & 79 & 79 \\
\hline \multicolumn{5}{|c|}{ EDTA addition $(n=36)$} \\
\hline$\%$ Positive & 39 & 39 & 36 & 36 \\
\hline$\%$ Wk Pos. & 28 & 19 & 22 & 22 \\
\hline$\%$ Negative & 33 & 42 & 42 & 42 \\
\hline \multicolumn{5}{|c|}{ DTT addition $(\mathrm{n}=21)$} \\
\hline$\%$ Positive & 52 & & 43 & 62 \\
\hline$\%$ Wk Pos. & 29 & & 38 & 29 \\
\hline$\%$ Negative & 19 & & 19 & 10 \\
\hline
\end{tabular}

${ }^{\mathrm{a}}$ Concentration in the final reaction mixture.

the plaque samples and indicates that the saliva was not contributing to the BANA hydrolysis of our subgingival samples.

\section{Discussion.}

Several studies have demonstrated that the number and proportions of spirochetes can be used to distinguish between healthy or periodontally diseased patients (Listgarten and Hellden, 1978; Loesche et al., 1985; Slots et al., 1985). However, spirochetes may not be the exclusive microbial indicator of periodontal disease, since $B$. gingivalis, $B$. forsythus, $H$. actinomycetemcomitans, and others have also been associated with periodontal diseases. Thus, it may be necessary to develop a test that will detect and quantitate most if not all of these species. This BANA assay, while correlating significantly with plaque levels and proportions of spirochetes, has the potential to detect the presence in high numbers of other species, such as $B$. gingivalis and $B$. forsythus, that are capable of degrading BANA (Loesche et al., 1986). In this capacity, the BANA test may provide a simple means of diagnosing an anaerobic infection involving these periodontopathogens.

The characteristics of the BANA reactions from subgingival plaque samples were investigated in this study in order to optimize the conditions for this assay. The concentration of BANA over the range of $0.67 \mathrm{mmol} / \mathrm{L}$ to $13.4 \mathrm{~mm} / \mathrm{L}$ was not critical, and the level of $0.67 \mathrm{mmol} / \mathrm{L}$ was chosen for further testing, since it yielded the maximal amount of hydrolysis per amount of substrate used (Table 1).

The importance of spirochetes was demonstrated when the ratio of positive and negative BANA results was compared as a function of the number of spirochetes or bacteria per hpf (Table 3). The importance of spirochetes was also shown by the findings obtained with the supragingival plaque samples. With these, there was no relationship between bacterial numbers and BANA hydrolysis, while there was a highly significant positive association between BANA hydrolysis and spirochetes per hpf and \% spirochetes (Table 6). In this respect, we concluded that the BANA hydrolysis was directly related to the number of spirochetes in both subgingival and supragingival plaque samples.

This analysis showed that the detection limit for the spirochetes was in the vicinity of 2 spirochetes per hpf, since $90 \%$ of the positive reactions had 2 or more spirochetes per hpf (Table 3). This value was also suggested by the dilution experiments, since BANA-positive samples converted to BANAnegative samples when the samples were diluted to $1.3 \mathrm{spi}$ rochete and 2.7 bacteria per hpf (Table 4 ). These spirochetal numbers are comparable with the 2 to 3 spirochetes per hpf that had previously been observed with single plaque samples taken from the most diseased sites per quadrant (Loesche et al., 1987). Thus, by including multiple subgingival plaque samples that were not necessarily taken from the most diseased sites, we could obtain results similar to those obtained when only single sites were sampled.

Among the cultivable spirochetes-i.e., T. socranskii, $T$. vincenti, $T$. pectinovorum, and $T$. denticola - only $T$. denticola hydrolyzes BANA (Syed et al., 1987, unpublished data). This would suggest the importance of $T$. denticola in the diseased sites. In this regard, Simonson et al. (1987) have shown, using monoclonal antibodies to $T$. denticola, that the numbers of this species increased significantly both in absolute numbers and relative numbers in samples taken from sites exhibiting periodontitis as opposed to gingivitis.

These results do not rule out the possibility that other bacteria were contributing to the positive BANA results. A previous investigation had shown that $B$. gingivalis and $C$. gingivalis were minor contributors to the BANA positiveness of plaque (Loesche et al., 1987). This leaves the recently described species, $B$. forsythus, and other unrecognized bacteria, as well as uncultivable spirochete species, as potential contributors to the BANA reaction.

BANA and BAPNA substrates were both readily hydrolyzed by plaque. However, BANA was the substrate of choice, because any blood in the sample gave a pale yellow color which was indistinguishable from the pale yellow color associated with a weak BAPNA result. Accordingly, in the presence of any blood, it would be difficult to recognize a weak BAPNA reaction by the plaque.

There was no significant effect on the BANA reactions of the various pHs that would be encountered in the plaque. The trypsin-like enzyme recently isolated from $B$. gingivalis (Yoshimura et al., 1984) is stimulated by DTT and EDTA and unaffected by $\mathrm{CaCl}_{2}$, whereas the $T$. denticola enzyme (Ohta et al., 1986) is unaffected by DTT and EDTA and activated by $\mathrm{CaCl}_{2}$. In our study, EDTA and $\mathrm{CaCl}_{2}$ gave a slight inhibition and DTT a slight enhancement of the BANA reaction by the pooled plaque suspensions (Table 8 ). Thus, the ingredients in the RTF did not seem to affect the results, nor did their addition suggest whether the $T$. denticola or $B$. gingivalis enzyme was the dominant enzyme in the plaque.

Analysis of these data indicates that BANA hydrolysis by pooled subgingival plaque samples is a suitable test for the detection of spirochetes when at least 2 or 3 spirochetes per hpf are present in the sample. The assay can best be performed with $0.67 \mathrm{mmol} / \mathrm{L}$ BANA at $\mathrm{pH} 7.0$, although there appears to be a wide range of substrate concentrations and $\mathrm{pHs}$ at which the enzyme is active.

The following instances are examples of when or where the BANA test could be applied in periodontal therapy: (a) at initial diagnosis, in conjunction with clinical parameters, so as to establish treatment tactics; (b) to determine whether initial treatment has been adequate or whether additional modalities are called for; (c) at recall visits, to determine whether retreatment is necessary; and (d) to predict possible future development of periodontal inflammation or periodontal breakdown. In this regard, the predictive value of clinical parameters is minimal in anticipating attachment loss in untreated patients (Haffajee et al., 1983).

Loesche et al. (1987) have shown that BANA hydrolysis by plaque samples has the potential to be a marker of periodontal morbidity as assessed by probing depth measurements and by plaque proportions of spirochetes. Syed et al. (1984) have shown that BANA hydrolysis can be used to measure the efficacy of antimicrobial treatment in the experimental gingivitis 
model. Gusberti et al. (1986) have shown that BANA hydrolysis along with other enzyme markers can be used to diagnose and to monitor treatment efficacy in refractory patients. Thus, the clinical management of patients with periodontal disease can be based on criteria given by both bacterial and clinical parameters that can be compared at different time intervals, as was suggested by Listgarten (1986).

In summary, the BANA test is simple to perform, of low cost, and could be useful for the dental profession as a parameter for diagnosing and monitoring the levels of spirochetes in subgingival plaque samples. The sensitivity and specificity of the BANA test are being evaluated in ongoing clinical studies in our laboratory.

\section{Acknowledgments.}

We would like to thank Drs. E. Schmidt, E. Chaves, J. Johnston, J. Schwartz, J. Giordano, B. Steffenson, G. Anderson, and Ms. Debra Stults for the collection of plaque samples.

\section{REFERENCES}

DZINK, J.L.; TANNER, A.C.R.; HAFFAJEE, A.D,; and SOCRANSKY, S.S. (1985): Gram-negative Species Associated with Active Destructive Periodontal Lesions, J Clin Periodontol 12:648659.

GUSBERTI, F.A.; SYED, S.A.; HOFMANN, T.; and LANG, N.P. (1986): Diagnostic Methods for the Assessment of Potential Periodontal Activity: Enzymatic Activities of Bacterial Plaque and their Relationship to Clinical Parameters. In: The Borderland Between Caries and Periodontal Disease III, T. Lehner and G. Cimasoni, Eds., Geneva: Editions Médécine et Hygiene, pp. 383 390.

HAFFAJEE, A.D.; SOCRANSKY, S.S.; and GOODSON, J.M. (1983): Clinical Parameters as Predictors of Destructive Periodontal Disease Activity, $J$ Clin Periodontol 10:257-265.

LAUGHON, B.E.; SYED, S.A.; and LOESCHE, W.J. (1982a): APIZYM System for Identification of Bacteroides spp., Capnocytophaga spp., and Spirochetes of Oral Origin, $J$ Clin Microbiol 15:97-102.

LAUGHON, B.E.; SYED, S.A.; and LOESCHE, W.J. (1982b): Rapid
Identification of Bacteroides gingivalis, $J$ Clin Microbiol 15:345346.

LISTGARTEN, M.A.(1986): A Perspective on Periodontal Diagnosis, J Clin Periodontol 13:175-181.

LISTGARTEN, M.A. and HELLDEN, L. (1978): Relative Distribution of Bacteria at Clinically Healthy and Periodontally Diseased Sites in Humans, $J$ Clin Periodontol 5:115-132.

LOESCHE, W.J. (1986): The Identification of Bacteria Associated with Periodontal Disease and Dental Caries by Enzymatic Activity Methods, Oral Microbiol Immunol 1:65-70.

LOESCHE, W.J.; SYED, S.A.; SCHMIDT, E.; and MORRISON, E.C. (1985): Bacterial Profiles of Subgingival Plaques in Periodontitis, $J$ Periodontol 56:447-456.

LOESCHE, W.J.; SYED, S.A.; and STOLL, J. (1987): Trypsin-like Activity in Subgingival Plaque - A Diagnostic Marker for Spirochetes and Periodontal Disease?, J Periodontol 58:266-273.

OHTA, K.; MAKINEN, K.K.; and LOESCHE, W.J. (1986): Purification and Characterization of an Enzyme Produced by Treponema denticola Capable of Hydrolyzing Synthetic Trypsin Substrates, Infect Immun 53:213-220.

SIMONSON, L.G.; GOODMAN, C.H.; MORTON, H.E.; and ROUSE, R.F. (1987): Quantitative Estimation of Treponema denticola in Adult Subgingival Plaque, $J$ Dent Res 66:169, Abst. No. 499.

SLOTS, J.; EMRICH, L.J.; GENCO, R.J.; and ROSLING, B.G. (1985): Relationship Between Some Subgingival Bacteria and Periodontal Pocket Depth and Gain or Loss of Periodontal Attachment After Treatment of Adult Periodontitis, $J$ Clin Periodontol $12: 540-552$.

SYED, S.A.; GUSBERTI, F.A.; LOESCHE, W.J.; and LANG, N.P. (1984): Diagnostic Potential of Chromogenic Substrates for Rapid Detection of Bacterial Enzymatic Activity in Health and Disease Associated Periodontal Plaques, $J$ Periodont Res 19:618-621.

SYED, S.A.; SALVADOR, S.L.; MAKINEN, K.K.; MAKINEN, P.-L.; and LOESCHE, W.J. (1987): Biochemical Comparison of Peptidases in Oral Treponema sp., ASM Abst 87:No. K137.

TANNER, A.C.R.; STRZEMPKO, M.N.; BELSKY, C.A.; and McKINLEY, G.A. (1985): API ZYM and API An-Ident Reactions of Fastidious Oral Gram-negative Species, J Clin Microbiol 22:333335.

YOSHIMURA, F.; NISHIKATA, M.; SUZUKI, T.; HOOVER, C.I.; and NEWBRUN, E. (1984): Characterization of a Trypsin-like Protease from the Bacterium Bacteroides gingivalis Isolated from Human Dental Plaque, Arch Oral Biol 29:559-564.

ZAMBON, J.J. (1985): Actinobacillus actinomycetemcomitans in Human Periodontal Disease, $J$ Clin Periodontol 12:1-20. 